\title{
MAPEAMENTO DE INSTITUIÇÕES SOCIOASSISTENCIAIS E DE SAÚDE \\ QUE TRABALHAM COM ADOLESCENTES EM SITUAÇÃO DE RUA EM \\ FEIRA DE SANTANA - BA
}

\author{
Sidney Sheldon Oliveira Bessa ${ }^{1}$; Rosely Cabral de Carvalho ${ }^{2}$; Givanildo da Silva \\ Nery ${ }^{3}$ e Jordyr Matheus Magalhães Rocha ${ }^{4}$ \\ 1. Bolsista PIBIC/CNPq, Graduando em Medicina, Universidade Estadual de Feira de Santana, e-mail: \\ ssobessa@gmail.com \\ 2. Orientador, Departamento de Saúde, Universidade Estadual de Feira de Santana, e-mail: \\ roselycarvalho056@gmail.com \\ 3. Participante do Núcleo Interdisciplinar de Estudos sobre Violência e Saúde, Departamento de Saúde, Universidade \\ Estadual de Feira de Santana, e-mail: \\ givanildogsn@hotmail.com \\ 4. Participante do Núcleo Interdisciplinar de Estudos sobre Violência e Saúde, Departamento de Saúde, Universidade \\ Estadual de Feira de Santana, e-mail: \\ jordyr_12@hotmail.com
}

PALAVRAS-CHAVE: adolescente; situação de rua; instituições.

\section{INTRODUÇÃO}

A necessidade de proteção de crianças e adolescentes é evidente na atualidade e imprescindível para as dinâmicas sociais, já que envolve diversas áreas do conhecimento, como a educação e a saúde, as quais analisam a situação dos mesmos, levando a promoção de medidas que objetivam suprir suas necessidades, garantir o desenvolvimento ideal, fornecer oportunidades de inserção social e certificar a ocorrência de todo esse processo buscando corrigir possíveis carências. Ao mesmo tempo, é necessário que as políticas públicas sejam articuladas e operantes buscando, assim, dar o suporte adequado àqueles indivíduos vulneráveis considerando a integralidade como propõe o Estatuto da Criança e do Adolescente (Lima \& Capellini, 2011).

Moura, Silva \& Noto (2009) trazem que o a apropriação da rua por crianças e adolescentes vai além de questões como moradia e sobrevivência, configurando-se também como uma rede de existência social, que podem levar a formas diversas e conflitantes de vida, se constituindo como uma cultura alternativa que auxilia no processo de adaptação social às realidades onde riscos e vulnerabilidades são mais difíceis e antagônicos.

Gracianni (1997) observa que os meninos de rua são vistos como personagens de características negativas, marginais e malandros, evidenciando um desvio social do papel de cidadão e pessoa humano, sendo afastados do contato e convívio social, reforçando o distanciamento das instituições de apoio e serviços disponíveis ao público que é excluído, vulnerável e sujeito as mais diversas fatalidades e riscos.

Com base nessas ideias, o trabalho "A inclusão social de adolescentes em situação de rua: vulnerabilidades e práticas de saúde" buscou entender aspectos que permeiam a vida de 
adolescentes em situação de rua, analisando as instituições responsáveis por prestação de serviços socioassistenciais e de saúde a essa parte da população mais vulnerável.

\section{METODOLOGIA}

Para realização das atividades do trabalho, houve reuniões e encontros com os estudantes, orientadora, e parceiros envolvidos a fim de preparar a etapa de coleta de dados e aplicação de questionários junto aos adolescentes em situação de rua. Nessas reuniões, foi discutido aspectos da metodologia Respondent Driven Sampling (RDS): como se constitui, como funciona, quais as vantagens e os desafios oferecidos. Os envolvidos foram preparados acerca do tipo de abordagem que deveria ser utilizada com os adolescentes para tornar o diálogo e assegurar a coleta de dados.

Foi aplicado um questionário com perguntas sobre informações gerais do adolescente como idade, sexo, escolaridade; perguntas sobre os motivos que o levaram a situação de rua, qual o tempo de permanência na rua, o que o mesmo faz nesse ambiente, quais situações se submetem, riscos e danos, aspectos sobre violência, uso de substâncias psicoativas (SPA); e perguntas sobre instituições que prestam serviços aos mesmos.

Após a coleta, o $\mathrm{s}$ dados foram organizados em um banco e serviram para análise sobre os diversos campos pesquisados, onde foram comparados, agrupados e discutidos.

\section{RESULTADOS E DISCUSSÃO}

Os dados da pesquisa foram coletados no município de Feira de Santana, por meio de um levantamento com 86 adolescentes em situação de rua. O mapeamento territorial e divisão geográfica do território foi feito junto a instituições parceiras, instituições socioeducativas e/ou centros de referência acolhedores de adolescentes em situação de rua, movimento população em situação de rua, Centros de Referências Especializados para Pessoas em Situação de Rua e secretaria de desenvolvimento social.

Foram definidos 10 territórios e regiões da cidade sendo 4 feiras livres, 3 grandes sinaleiras, 2 praças e 1 terminal rodoviário. Os sujeitos da pesquisa foram adolescentes em situação de rua, com faixa etária entre 12 a 19 anos.

Foram definidas três tipologias de adolescentes em situação de rua segundo as ideias apresentadas por Martins (1996) e adaptas segunda a necessidade apresentada pelo contexto em que o levantamento dos dados se encontrava.

Tipo 1 - Adolescentes que buscam renda para família e/ou para seu próprio sustento (trabalho de caráter diurno), alimentam-se nas ruas, costumam chegar tarde da noite em casa, para dormir e têm lazer no bairro onde moram. Vínculo familiar instável.

Tipo 2 - Adolescentes que buscam renda para família e/ou para seu próprio sustento (trabalho durante o dia, nas feiras livres), acompanhados de familiares e/ou outras 
pessoas, alimentam-se e dormem em casa, mas têm lazer constante nas ruas. Vínculo familiar estável.

Tipo 3 - Adolescentes que buscam renda para seu próprio sustento (atividades diversas nas principais nas sinaleiras), alimentam-se e dormem em casa e migram, constantemente, de atividades, espaços geográficos e horários que exercem suas funções, em virtude de conflitos familiares, disputas por territórios ou diminuição do lucro e têm lazer nos espaços públicos ou nas ruas. Vínculo Familiar instável

Na coleta de dados durante o dia foram entrevistados adolescentes em situação de rua (tipologias 2 e 3). Os locais foram as sinaleiras e feiras livres, caracterizados por serem espaços de renda dos adolescentes e seus familiares, sejam vendendo alimentos ou outras atividades como limpar vidros, lavar e vigiar carros.

$\mathrm{Na}$ coleta ocorreram três momentos de entrevistas com adolescentes em pontos específicos como a rodoviária, e as praças, espaços onde as atividades de exploração sexual, comercial e de maior uso de drogas têm destaque, e os adolescentes se enquadram como de situação de rua da tipologia 1.

Os adolescentes (tipologia 2 e 3 ) permanecem um maior tempo nas ruas, chegando entre cinco e sete da manhã e retornando no fim da tarde, com a justificativa de procurar sustento para si e para sua família. Na rua, são chefiados por algum adulto na maioria dos casos, podendo este ser da família ou apenas o responsável do negócio. Por mais que possuam uma relação inerente ao lugar onde passam a maior parte do tempo, esses indivíduos demonstram uma preocupação e buscam criar vínculos entre si, configuradas como uma rede de apoio, uma "família" reserva. Os pontos de maior risco ao uso de drogas e prostituição, os hábitos de vida dos adolescentes (tipologia 1) eram diferentes: eles dormem nas ruas, ficam até a madrugada vendendo doces na rodoviária, frequentam diferentes pontos de prostituição, ou seja, possuem estilos variados de vida. Percebe-se uma maior liberdade desses indivíduos: eles possuem autonomia nas decisões segundo seus desejos. Nesses locais, a aproximação com os elementos que configuram o espaço rua levam a um afastamento do indivíduo com sua família, e devido a desconfiança e o medo de reviver situações de agressão e violência, não buscam proximidade.

Mesmo que todos os entrevistados fossem adolescentes em situação de rua, os riscos e as dinâmicas sociais a que estão submetidos são diferentes, o que torna o comportamento e as práticas de vidas de cada um algo ímpar em seus relatos e comportamentos.

\section{CONSIDERAÇÕES FINAIS}

Percebe-se com os dados obtidos que os adolescentes (tipologia 2 e 3) permanecem um maior tempo nas ruas com a justificativa de procurar sustento para si e para sua família, enquanto os adolescentes (tipologia 1) dormem nas ruas, ficam até a madrugada vendendo doces na rodoviária, frequentam diferentes pontos de prostituição, resultando em 
diferentes estilos de vida entre indivíduos da mesma tipologia, e até mesmo entre as três tipologias relacionada a pesquisa.

\section{REFERÊNCIAS}

CARVALHO, R. C.; NERY, G. S.; SOUZA, S. L.; SILVA, C. A. L. (2017). A Contribuição Teórico-Metodológica do Respondent- Driven Sampling (RDS) em Pesquisa com Adolescentes em Situação de Rua em Feira de Santana, Bahia.

LIMA, A. B.; CAPELLINI, V. L. M. F. (2011) Situação de rua e evasão escolar: Atenção para saúde inclusiva. Debates em Educação. Maceió, v.3, n.5, p. 35-48

GRACIANI, M.S.S. (1997). Pedagogia Social de Rua: análise e sistematização de uma experiência vivida. São Paulo: Editora Cortez: Instituto Paulo Freire.

MARTINS, R.A. (1996). A Criança e o Adolescente em Situação de Rua: Definições, Evolução e Políticas de Atendimento. COLETANEAS DA ANPEPP, v. 1, n.12, p. 3544.

MOURA, Y. G.; SILVA, E. A.; NOTO, A.R. (2009). Redes sociais no contexto de uso de drogas entre crianças e adolescentes em situação de rua: the context of drug use among children and adolescents at street circunstancie. Psicol. Pesq., Juiz de Fora, v. 3, n. 1, p. 31-46, jun. 